\title{
Explaining social presence and the quality of online learning with the SIPS model
}

Citation for published version (APA):

Weidlich, J., \& Bastiaens, T. (2017). Explaining social presence and the quality of online learning with the SIPS model. Computers in Human Behavior, 72, 479-487. https://doi.org/10.1016/j.chb.2017.03.016

DOI:

10.1016/j.chb.2017.03.016

Document status and date:

Published: 01/07/2017

Document Version:

Version created as part of publication process; publisher's layout; not normally made publicly available

\section{Document license:}

CC BY

Please check the document version of this publication:

- A submitted manuscript is the version of the article upon submission and before peer-review. There can be important differences between the submitted version and the official published version of record. People interested in the research are advised to contact the author for the final version of the publication, or visit the DOI to the publisher's website.

- The final author version and the galley proof are versions of the publication after peer review.

- The final published version features the final layout of the paper including the volume, issue and page numbers.

Link to publication

\section{General rights}

Copyright and moral rights for the publications made accessible in the public portal are retained by the authors and/or other copyright owners and it is a condition of accessing publications that users recognise and abide by the legal requirements associated with these rights.

- Users may download and print one copy of any publication from the public portal for the purpose of private study or research.

- You may not further distribute the material or use it for any profit-making activity or commercial gain

- You may freely distribute the URL identifying the publication in the public portal.

If the publication is distributed under the terms of Article 25fa of the Dutch Copyright Act, indicated by the "Taverne" license above, please follow below link for the End User Agreement:

https://www.ou.nl/taverne-agreement

Take down policy

If you believe that this document breaches copyright please contact us at:

pure-support@ou.nl

providing details and we will investigate your claim.

Downloaded from https://research.ou.nl/ on date: 26 Apr. 2023 
See discussions, stats, and author profiles for this publication at: https://www.researchgate.net/publication/314271998

\section{Explaining social presence and the quality of online learning with the SIPS} model

Article in Computers in Human Behavior · July 2017

Dol: 10.1016/j.chb.2017.03.016

CITATIONS

11

2 authors, including:

a.

Joshua Weidlich

Pädagogische Hochschule Heidelberg

12 PUBLICATIONS 28 CITATIONS

SEE PROFILE
READS

621

Some of the authors of this publication are also working on these related projects:

Enhancing Social Presence in Online Learning through the use of Social Software View project 
Full length article

\title{
Explaining social presence and the quality of online learning with the SIPS model
}

\author{
Joshua Weidlich*, Theo J. Bastiaens \\ Department of Instructional Technology and Media, FernUniversität Hagen, Universitätsstraße 33, 58084 Hagen, Germany
}

\section{A R T I C L E I N F O}

\section{Article history:}

Received 22 December 2016

Received in revised form

3 March 2017

Accepted 6 March 2017

Available online 6 March 2017

\section{Keywords:}

Social presence

Sociability

Social space

Partial least squares structural equation

modeling

Online learning

Satisfaction

\begin{abstract}
A B S T R A C T
The concept of Social Presence is often cited by researchers trying to understand the mechanisms governing beneficial learning climates and interpersonal connections among online learners. However, convoluted definitions and problematic measurements of social presence have made it difficult to understand how exactly social presence and related social variables come to be, hindering the investigation of reliable design recommendations. This study attempts to advance the SIPS (Sociability, Social Interaction, Social Presence, Social Space) model. It shows how these variables are related to each other and to relevant outcome variables like satisfaction. Partial Least Squares Structural Equation Modeling (PLSSEM) was used to assess the predictive capabilities of the model regarding the outcome variables. Results support the notion that a sociable learning environment fosters social interaction, leading to social presence and the emergence of a sound social space, in turn explaining the quality of the learning experience. Social presence, when measured in a non-convoluted way, has no effect on satisfaction.
\end{abstract}

๑) 2017 Elsevier Ltd. All rights reserved.

\section{Introduction}

Through the development of increasingly sophisticated technology and the simultaneous increasing prevalence of the Internet, the use of online technology to deliver instruction has continually increased over the past two decades (Allen \& Seaman, 2013; Forum Distance Learning, 2014; Snyder, Dillow \& Hoffmann, 2009). However, there are issues concerning the nature of mediated communication in learning. A common concern is, for example, that the mediated nature of online learning may hamper a sense of interpersonal connection and relatedness between students. Where face-to-face-learning offers a rich social context and opportunities to interact in a non-mediated fashion, online learning makes use of technology to mediate social interaction.

Researchers have turned to social presence theory in order to understand the mechanisms governing beneficial learning climates and interpersonal connections among online learners. As a consequence, social presence is now considered an important factor of successful online and distance learning. However, many unresolved issues remain.

This study attempts to advance the SIPS (Sociability, Social

\footnotetext{
* Corresponding author.

E-mail address: Joshua.Weidlich@fernuni-hagen.de (J. Weidlich).
}

Interaction, Social Presence, Social Space) model that deals with some of these issues by distinguishing social presence from other relevant social aspects of online learning. The model is analyzed with Partial Least Squares Structural Equation Modeling (PLS-SEM) and its predictive capabilities regarding the outcome variables satisfaction, perceived learning and confidence are assessed. The results suggest that creating a sociable learning environment is a viable approach to fostering socioemotional aspects that ultimately benefit the quality of the learning experience.

\section{Social presence research}

In 1976, Short, Williams, and Christie coined the term social presence, defining it as "the degree of salience of the other person in the communication and the consequent salience of the interpersonal relationships" (p.65). Two concepts associated with social presence are Wiener \& Mehribian's (1968) immediacy and Argyle and Dean's (1965) intimacy. Immediacy refers to the psychological closeness between communicators, whereas intimacy refers to the degree of affiliation between communicators.

As online learning has become more popular and technically sophisticated, research began considering socio-emotional aspects of online learning. Seeking to understand the relevance of social interaction and interpersonal relationships between online 
learners, scholar turned to social presence theory. Social presence has since been successfully linked to important outcome variables of online learning, e.g. satisfaction (Gunawardena \& Zittle, 1997), perceived learning (Richardson \& Swan, 2003), online course retention (Liu, Gomez, \& Yen, 2009) and online social interaction (Tu \& McIsaac, 2002). In addition to this, social presence has a prominent role in the community of inquiry (COI) framework, alongside teaching presence and cognitive presence (Garrison, Anderson, \& Archer, 2000; 2010). The COI framework posits that meaningful learning takes place when an online learning experience has sufficient amounts of all three presences.

As a consequence, social presence is now considered an important factor of successful online and distance learning (Garrison \& Arbaugh, 2007; Kim, 2010; Richardson, Swan, Lowenthal, \& Ice, 2016). However, several issues regarding the conception and measurement of social presence remain (Kreijns, Kirschner, Jochems, \& Van Buuren, 2011; Kreijns, Van Acker, Vermeulen, \& Van Buuren, 2014; Lowenthal, 2010; Lowenthal \& Dunlap, 2014).

\subsection{Convoluted definitions and problematic measurements}

As social presence theory stems from rather diverse lines of research (for reviews, see Lowenthal, 2010; Cui, Lockee, \& Meng, 2013), it is not surprising that the research literature has yielded a similarly diverse assortment of conceptions regarding social presence. Even though most scholars will attribute their understanding of social presence to the concept proposed by Short et al. (1976), there is no agreed upon and universally used definition. As Lowenthal (2010) points out: "Definitions of social presence, at least for researchers of social presence and online learning, tend to fall on a continuum" (p. 120). The continuum reaches from social presence as the salience of the other person in the interaction, whether someone is perceived as being "present" and "real", to social presence as the salience of the interpersonal relationships, including whether or not there is an interpersonal emotional connection. Note that these opposite ends of the continuum both represent an extension of the original Short et al. (1976) definition. Because most researchers tend to fall somewhere in the middle of this continuum (Lowenthal, 2010), many definitions of social presence are not only different from each other but also convoluted. Thus, Biocca, Harms, and Burgoon (2003) summarize that definitions of social presence are (a) vague, overly broad, or circular, and (b) blur the distinction between the psychological state of social presence and the behavioral effects thereof. This is a problem, because different and convoluted definitions of a construct will yield different and convoluted ways of measuring it, respectively.

Accordingly, there has been very little consistency in the way researchers have measured social presence. Seeking behavioral evidence, Rourke, Anderson, Garrison, and Archer (2001), analyzed text-based online discussion in search of indicators demonstrating social presence. They established twelve indicators, grouped into three categories (affective response, interactive response, and cohesive response) as evidence of social presence in online discussions. More recently, a COI survey instrument was developed (Arbaugh et al., 2008) and validated (Carlon, Bennett-Woods, \& Berg, 2012; Diaz, Swan, Ice, \& Kupczynski, 2010). However, this instrument is reported to still have issues regarding factor structure (Carlon et al., 2012) and its alignment with the social presence indicators (Lowenthal \& Dunlap, 2014).

Outside of the COI framework, other social presence surveys old and new - are abundant. Gunawardena (1995), Gunawardena and Zittle (1997), Tu (2002), Picciano (2002), Wei, Chen, and Kinshuk (2012) and Kim, Kwon, and Cho (2011) all developed different questionnaires to assess social presence. Because these measures are based on convoluted definitions of social presence, they too may be convoluted. Indeed, Kreijns et al. (2011) and Kreijns et al. (2014) show that many of these measures do not exclusively measure social presence, but instead "measure varying aspects of an amorphous set of variables - including social presence, to varying degrees (p.371). This a problem when trying to empirically link desirable outcome variables (e.g. satisfaction) to social presence. How can researchers reliably rule out that these effect aren't in fact a result of the hidden variables in social presence scales?

\subsection{Untangling social presence and social space}

Alternatively, there are strong arguments for distinguishing two important variables in online learning. These two variables can be directly traced back to the two-step definition of Short et al. (1976), namely (1) the salience of the other in the communication and (2) the consequence of this, the salience of the interpersonal relationship. This means restricting social presence to the first part of this definition, the "presentness" and "realness" of the other, as proposed by Kreijns et al. (2011). In this understanding, social presence is the illusion of non-mediation; although participants are aware of using mediated communication, they may perceive the communication partner as actually real and present, not unlike face-to-face communication. This sensation may come about by a process called impression formation (Walther, 1993). Connected but not identical to social presence is the second part of the definition, in which a learner may feel that there is an interpersonal relationship with a communication partner. As a perceived relationship creates a tie between communication partners, a network of interpersonal relationships may develop between learners in online learning. This network is called a social space (Kreijns, Kirschner, Jochems, \& Van Buuren, 2004).

Besides the basic argument, that researchers, in order to establish meaningful empirical and theoretical connections, should strive for validity in their measurements, there are three additional arguments for the distinction of social presence and social space.

(1) Research should build on the existing body of literature concerning social aspects like group cohesion, sense of community and learning climate in online learning that has established relationships to satisfaction (Dewiyanti, BrandGruwel, Jochems, \& Broers, 2007; Wu, Tennyson, \& Hsia, 2010) and perceived learning (Rovai, 2002). These constructs are similar or possibly even identical to social space. By confounding these variables with social presence, researchers have done little to achieve clarity.

(2) A recent meta-analysis by Richardson, Maeda, Lv, and Caskurlu (2017) has shown that the relationship between social presence and satisfaction is highly variable, with the scale type being a significant moderator of this relationship. This is unsurprising, when considering that these measures are mostly based on convoluted definitions of social presence. If future research does not differentiate these social constructs in a clear and transparent fashion, research results will continue to be highly variable, thereby hindering a solid foundation of research.

(3) There is an obvious pragmatic benefit. It is much easier to explain and measure two distinguishable concepts, rather than a single concept with multiple, still widely contested dimensions. Although multidimensional constructs are not uncommon in psychological research, it seems that in social presence research, the explanatory potential of this complexity falls short of being an improvement. Instead, it seems to have caused confusion, as illustrated in the differences of operationalization between researchers. 


\subsection{Social presence and social interaction}

Many researchers have mentioned the close relationship between social presence and social interaction. However, similar to the epistemic status of social presence, the relationship between these two constructs remains contested. Tu (2002) holds that interaction contributes to social presence. In another study, Tu and McIsaac (2002) state that "an increase in the level of online interaction occurs with an improved level of social presence" (p.131), thereby steering clear of causal assumptions. Wei et al. (2012) however, propose a causal model in which social presence is a predictor variable for learning interaction. Similarly, Hostetter and Busch (2006) also argue that social presence directly leads to social interaction. In contrast, Biocca et al. (2003) state, that social presence theory is the theory of mediated social interaction and therefore includes the concept of interaction. Gunawardena (1995) is less concrete in detailing the role of interaction by stating that "social presence is a factor of the medium, as well as that of the communicators and their presence in a sequence of interaction" (p.151).

Different wordings and causal assumptions aside, it should be noted that social presence is primarily concerned with studentstudent interaction, according to Moore's (1989) classic distinction of types of interaction in online and distance learning. This type of interaction should be called social interaction to encapsulate all possible types of interaction between students, not only interactions regarding the content or learning task, but also informal, personable types of social interaction. Kreijns, Kirschner, and Jochems (2002) propose a classification of social interaction, in which types of interaction may be distinguished by context (task vs non-task) and dimension (cognitive vs socio-emotional). Depending on which type of social interaction is dominant, the learning experience and learning environment will be different.

This research is not concerned with a specific kind of social interaction, but instead with all types of interactions that may occur between students, for example asynchronous communication via message board or synchronous communication in a chat session. Because social interaction is always the first step in forming an impression of another person (i.e. there is simply no contact without social interaction), it is also an important precursor for the emergence of social presence. Hence, in this research social interaction is understood to lead to social presence, instead of being a result of or being interleaved with social presence.

\subsection{The SIPS model for social aspects of online learning}

Because there is little agreement on many basic aspects surrounding social presence research, it is difficult to investigate reliable design recommendations to facilitate social aspects in online learning (Cui et al., 2013). Hence, a coherent model or framework encompassing the relevant socio-emotional variables and their relationships is in order.

Kreijns et al. (2004); Kreijns, Kirschner, \& Vermeulen, (2013) propose one such framework for computer-supported collaborative learning (CSCL) environments. It contains the relevant social variables and their relationships to each other. The framework has advantages over other frameworks by actually suggesting an explanation of how these aspects come to evolve. Some but not all of these relationships have been empirically supported through previous research (for a detailed discussion, see Kreijns et al., 2013). Since much of social presence research has been conducted without specifically having a CSCL context in mind, an adaptation to explain and predict socio-emotional aspects for online and distance learning is still needed. This adaption, called the SIPS model (for Sociability, Social Interaction, Social Presence, and Social Space), is

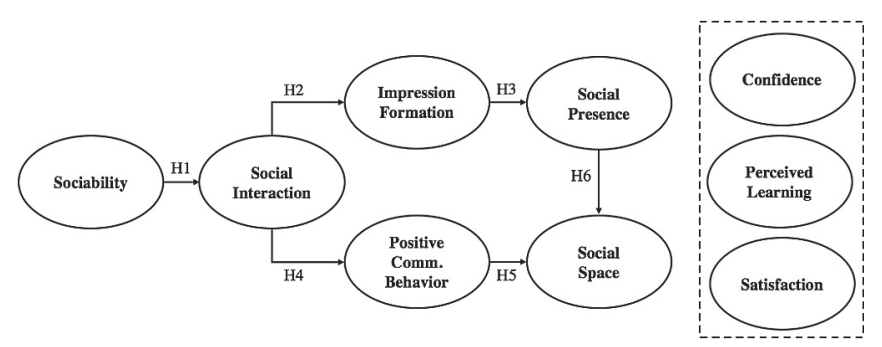

Fig. 1. The SIPS model for Online Learning, adapted from Kreijns et al. (2013).

shown in Fig. 1. The relevant variables and their definitions are listed in Table 2.

The model is based on an ecological approach to fostering social aspects. Here, the sociability of the learning environment is expected to be a predictor for how much social interaction will take place because learning in sociable environment will facilitate and promote social interaction (H1). This will in turn foster the emergence of social presence $(\mathrm{H} 2-\mathrm{H} 3)$ and the development of a sound social space (H4-H5). The emergence of social presence is determined by a process called impression formation. When social interaction takes place, communicators will form an increasingly distinct impression of one another ( $\mathrm{H} 2)$. As these impressions become increasingly salient through ongoing social interaction, a perception of non-mediation -social presence-will emerge (H3). When meaningful social interaction takes place, learners will come to demonstrate positive communicative behavior that is indicative of a positive climate and strong group cohesion (H4). Perceiving these behaviors, learners will attest to the development of a sound social space (H5). Additionally, feelings of social presence will facilitate the development of a sound social space by evoking a sense of face-to-face conversation (H6).

This model is streamlined in three ways. (1) It excludes the variables social affordances and pedagogical techniques, as these factors are beyond the research interest of this study. (2) Also, the model doesn't account for bidirectional relationships, but instead focuses on the expected primary causal flow of constructs. (3) In addition, it departs from Kreijns et al. $(2004 ; 2013)$ by not expecting sociability to be a direct precursor to social presence. The original model holds that sociability will influence social presence directly, as well as through social interaction. However, sociability as the perceived quality of the learning environment to support social interaction (Kreijns et al., 2004), by definition is not expected to influence social presence directly, but only through social interaction (see chapter 2.3). In this conception, sociability will only be perceived by the learner to the extent that he may have a higher incentive to interact socially with his peers.

\section{Method}

This method sections describes the research questions and hypotheses, the data collection procedure, as well as the instruments used.

Table 1

Factor Analysis of new items.

\begin{tabular}{llll}
\hline & $\begin{array}{l}\text { KMO-Sampling } \\
\text { Adequacy }\end{array}$ & $\begin{array}{l}\text { Variance accounted } \\
\text { for }\end{array}$ & $\begin{array}{l}\text { Items } \\
\text { deleted }\end{array}$ \\
\hline $\begin{array}{l}\text { Satisfaction } \\
\text { Perceived } \\
\text { Learning }\end{array}$ & 0.824 & $59,2 \%$ & 3,6 \\
$\begin{array}{c}\text { Pos. Comm. } \\
\text { Behav. }\end{array}$ & 0.756 & $66,8 \%$ & - \\
Confidence & 0.686 & $62,2 \%$ & 4 \\
\hline
\end{tabular}


Table 2

List of variables for this research.

\begin{tabular}{|c|c|c|c|}
\hline Variable & Description & Measure & Example Item \\
\hline Sociability & $\begin{array}{l}\text { The perceived quality of the learning } \\
\text { environment to } \\
\text { facilitate social interaction. }\end{array}$ & $\begin{array}{l}\text { Kreijns, Kirschner, Jochems, and Van } \\
\text { Buuren (2007), adapted for non-CSCL context; }\end{array}$ & $\begin{array}{l}\text { "This learning environment allows for spontaneous } \\
\text { informal conversation" }\end{array}$ \\
\hline $\begin{array}{l}\text { Social } \\
\quad \text { Interaction }\end{array}$ & $\begin{array}{l}\text { The amount and frequency of } \\
\text { communication } \\
\text { between a given student and his peers. }\end{array}$ & Wei et al. (2012) & "I often discussed learning issues with others" \\
\hline $\begin{array}{l}\text { Impression } \\
\text { Formation }\end{array}$ & $\begin{array}{l}\text { The degree to which students have } \\
\text { gathered a distinct } \\
\text { impression of their peers. }\end{array}$ & New measure, similar to Walther (1993) & $\begin{array}{l}\text { "I have a distinct impression of the appearance of the } \\
\text { other student" }\end{array}$ \\
\hline $\begin{array}{l}\text { Social } \\
\text { Presence }\end{array}$ & $\begin{array}{l}\text { The psychological sensation of the other } \\
\text { being } \\
\text { "there" and "present". }\end{array}$ & $\begin{array}{l}\text { Kreijns et al. (2011), adapted for } \\
\text { non-CSCL context }\end{array}$ & $\begin{array}{l}\text { "When I have asynchronous conversations, I feel that I } \\
\text { deal with very real persons and not with abstract } \\
\text { anonymous persons" }\end{array}$ \\
\hline $\begin{array}{l}\text { Pos. Comm. } \\
\text { Behavior }\end{array}$ & $\begin{array}{l}\text { The degree to which positive and } \\
\text { constructive } \\
\text { communications } \\
\text { are perceived. }\end{array}$ & New measure & $\begin{array}{l}\text { "The discussions and conversations that I was aware of } \\
\text { were always friendly and constructive" }\end{array}$ \\
\hline Social Space & $\begin{array}{l}\text { The network of interpersonal relationships } \\
\text { between students. }\end{array}$ & $\begin{array}{l}\text { Kreijns et al. (2004), adapted for } \\
\text { non-CSCL context }\end{array}$ & "Students took the initiative to get in touch with others" \\
\hline $\begin{array}{l}\text { Perceived } \\
\text { Learning }\end{array}$ & $\begin{array}{l}\text { The extent to which the student feels he has } \\
\text { gained knowledge } \\
\text { about the class subject. }\end{array}$ & New measure & $\begin{array}{l}\text { "When thinking about my learning in this online class, } \\
\text { I would consider it a success"” }\end{array}$ \\
\hline Satisfaction & $\begin{array}{l}\text { The extent to which the student is content } \\
\text { regarding all aspects } \\
\text { of the learning experience. }\end{array}$ & New measure & "This online class met my expectations" \\
\hline Confidence & $\begin{array}{l}\text { The extent to which the student has an } \\
\text { optimistic view regarding } \\
\text { his/her mastery of the subject. }\end{array}$ & New measure & $\begin{array}{l}\text { "I feel that I am able to competently answer questions about } \\
\text { the content of this online class" }\end{array}$ \\
\hline
\end{tabular}

\subsection{Research questions and hypotheses}

The SIPS model has not been subject to validation attempts. For this reason and because it has been adapted in the previously mentioned ways, the first research question concerns the validity of the model. The model is valid if the hypothesized relationships are consistent with the data $(\mathrm{H} 1, \mathrm{H} 2, \mathrm{H} 3, \mathrm{H} 4, \mathrm{H} 5, \mathrm{H} 6)$. This is true if the path coefficients are significant. In addition to this, the predictive capabilities of the model will be examined. This is done via effect sizes $\left(f^{2}\right)$ and explained variance $\left(R^{2}\right)$.

Because theoretical considerations make the often established effect of social presence on satisfaction questionable, this connection will be tested (H7). In addition, two other outcome variables will be investigated regarding their relationship to social aspects of online learning. As there is no established theory of how exactly the outcome variables are related to each other and to the model, there is only one other hypothesis. Common sense suggests that perceived learning is a predictor for satisfaction and confidence (H8).

RQ1. Is the SIPS-model of online learning valid and what are its predictive capabilities?

H1. Sociability is a predictor for social interaction in the learning environment

H2. Social Interaction predicts impression formation

H3. Impression formation predicts social presence

H4. Social interaction predicts positive communicative behavior

H5. Positive communicative behavior predicts a sound social space

H6. Social Presence predicts a sound social space

RQ2. How do the outcome variables relate to social aspects of online learning?
H7. Satisfaction is predicted by a sound social space instead of social presence

H8. Perceived learning is a predictor for confidence and satisfaction

\subsection{Data collection}

The data was collected in an Educational Science Bachelor's class at the largest German distance education university, FernUniversität Hagen. The class's primary learning activities take place in Moodle. Typical methods of communication are threaded message boards and bi-weekly non-mandatory chats. Data was collected over the course of one semester resulting in 162 responses. Online data collection via Limesurvey accounted for $42 \%$ of the data. Data collection via print survey accounted for the $58 \% .26 \%$ of participants were enrolled in a psychology bachelors program, $74 \%$ in an educational science bachelors program. Also, $75 \%$ of respondents were female, $25 \%$ male.

Results for Little's test for MCAR (missing completely at random) are not significant, Chi-Square $=3322,805, \mathrm{DF}=3401, \mathrm{p}=, 828$. Therefore, deletion of cases with too many missing variables is not expected to introduce bias (Allison, 2001; Graham, 2009). A threshold of $10 \%$ missing values per case was selected, resulting in the exclusion of 27 cases. The final amount of participants for this study is $\mathrm{n}=135$.

Sensitivity power analysis with $\mathrm{G}^{*}$ Power 3.1 (Faul, Erdfelder, Lang, \& Buchner, 2007) for linear multiple regression, fixed model $R^{2}$ deviation from zero, alpha level 0.05 , power $0.8, \mathrm{n}=135$, maximum number predictors 2 , calculates a sensitivity for effect sizes as low as $f^{2}=0.07$.

\subsection{Instruments}

Scales that have been previously validated were entered directly 
into the structural model. Therefore, social presence, social space, sociability and social interaction were assessed in the context of measurement model evaluation. However, some small modifications were necessary to account for the context of this sample. The social space scale was originally developed in a CSCL context. The items relating specifically to this context were excluded from data collection. Also, the Social Presence scale consists in part of items that directly relate to synchronous chat activities. As only $33 \%$ of participated in these non-mandatory chat activities during the semester, these items were also excluded from further analysis.

New items that have not yet been validated, were analyzed regarding their factor structure, using principal axis factoring, direct oblimin rotation with an eigenvalue of 1 . Impression formation was excluded from this, because it is a formative measure (see chapter 4.1). Table 1 shows the results of the analysis. In all cases, the Kaiser Mayer-Olkin Measure of Sampling Adequacy exceed 0.5, which is considered the threshold. Bartlett's Test of Sphericity is also significant at the 0,01 level in every case. Items correlating lower than 0.3 and factor loadings of less than 0.7 resulted in exclusion of the item.

To assess the normality of distribution in the data, KolmogorovSmirnov and Shapiro-Wilk test were applied. Significant values for the following scales suggest a possible non-normality: social presence, social interaction, perceived learning, positive communicative behavior, confidence. Therefore, additional graphical inspection of normality is warranted. Upon inspection of histograms and $\mathrm{Q}-\mathrm{Q}$ plots of the variables, non-normality was confirmed for social presence (positively skewed), social interaction (Kurtosis) and perceived learning (negatively skewed). Positive communicative behavior and confidence show no substantial deviation from normality.

\section{Analysis}

The Analysis was conducted via Partial Least Squares Structural Equation Modeling (PLS-SEM). PLS-SEM is a flexible and powerful approach to multivariate analysis and is widely used in many social science disciplines. Lately, the method has also become increasingly popular in educational research (e.g. Cao, Ajjna, \& Hong, 2013; Fillion, Limayem, Laferriere, \& Martha, 2009; Hamari et al., 2016; Wu et al., 2010). It differs from covariance-based approaches (CBSEM) by maximizing the explained variance of the dependent latent constructs. In this, it is most suitable to assess predictive capabilities of a hypothesized causal model. Hence, researchers should choose PLS-SEM over CB-SEM in situations in which the substantive theory is not yet fully developed and the primary goal is prediction of target constructs (Chin, 1998; Hair, Hult, Ringle, \& Sarstedt, 2014). As detailed in Chapter 2, social presence theory is still eclectic and the relationship of its key constructs to dependent variables is not yet fully understood. In addition to this, three major advantages of PLS-SEM are applicable in this research. (1) PLS-SEM works well with smaller sample sizes. Note, however, that the present sample size is well above any rule of thumb (Hair et al., 2014) (2) PLS-SEM makes no distributional assumptions, allowing for parameter estimation with non-normal data. As not all variables are normal in this research (see Chapter 3.3), a non-parametric approach is appropriate (Chin, 1998). (3) PLS-SEM is able to include formative measurement models into the structural model. As shown in Chapter 4.1, impression formation is measured formatively.

The assessment of a PLS model is a two-step process. In a first step, the measurement model is assessed in regard to reliability and validity. Once the measurement models adequacy is established, the second step is the assessment of the structural model for its capacity to predict outcome variables. Data was analyzed with SmartPLS 3.0 (Ringle, Wende, \& Becker, 2015).

\subsection{Measurement model evaluation}

Reliability of scales is assessed via Composite Reliability (Table 3). All scales are well above the threshold of 0.7. The validity of the measurements is assessed through convergent and discriminant validity. The average variance extracted (AVE) satisfies the requirement for convergent validity of 0.5 for all constructs, after weaker loading indicators $(<0.6)$ of the sociability and social space scale have been removed. The Fornell and Larcker (1981) criterion for discriminant validity requires that the values in the matrix diagonals are all greater than the off-diagonal elements (Table 3).

Whereas reflective measures are said to be caused by the underlying construct, formative measures represent instances in which the indicators themselves form the underlying construct (Hair, Ringle, \& Sarstedt, 2011). In contrast to reflective measures, the items in a formative measure are not interchangeable, might relate to very distinct aspects of perception, and therefore do not necessarily intercorrelate. As a result, the assessment of a formative measure differs from assessment of a reflective measure.

In the present model impression formation is measured formatively. We suggest that impression formation consists of gathering a rich set of impressions other learners. Taken together, these impressions constitute a mental model that one learner can have of the other. This approach is based on Walther's (1993) approach to measuring impression formation. The items were derived from characteristics that a student could gather of his peers through interacting in the learning environment, for example personality, competence, and age.

Convergent validity is demonstrated through significant correlations between the formative indicators and a global item ("I was able to gather rich impressions of my peers"). Table 4 shows that all formative indicators correlate with the global item for impression formation at the 0.001 level. Problems with collinearity can be assessed through Variance Inflation Factor (VIF). A VIF value lower than 0.2 or higher than 5 is said to be indicative of potential issues in this respect (Hair et al., 2014). Table 4 shows that no indicator

Table 3

Discriminant validity, average variance extracted, and Composite reliability.

\begin{tabular}{|c|c|c|c|c|c|c|c|c|c|c|}
\hline & 1 & 2 & 3 & 4 & 5 & 6 & 7 & 8 & AVE & $\mathrm{CR}$ \\
\hline Sociability (1) & 0.72 & & & & & & & & 0.52 & 0.90 \\
\hline Social Interaction (2) & 0.54 & 0.93 & & & & & & & 0.86 & 0.97 \\
\hline Social Presence (3) & 0.45 & 0.34 & 0.91 & & & & & & 0.82 & 0.90 \\
\hline Pos. Comm. Behav. (4) & 0.49 & 0.46 & 0.43 & 0.79 & & & & & 0.62 & 0.87 \\
\hline Social Space (5) & 0.49 & 0.42 & 0.44 & 0.70 & 0.76 & & & & 0.57 & 0.82 \\
\hline Perceived Learning (6) & 0.32 & 0.25 & 0.31 & 0.30 & 0.37 & 0.81 & & & 0.66 & 0.91 \\
\hline Satisfaction (7) & 0.42 & 0.18 & 0.32 & 0.52 & 0.48 & 0.64 & 0.77 & & 0.59 & 0.90 \\
\hline Confidence (8) & 0.29 & 0.32 & 0.32 & 0.46 & 0.37 & 0.49 & 0.33 & 0.86 & 0.73 & 0.90 \\
\hline
\end{tabular}


Table 4

Correlations with criterion item, outer loadings of indicators, and variance inflation factor.

\begin{tabular}{llll}
\hline & Correlation with criterion & Outer Loadings & VIF \\
\hline Name & $0.37^{* * *}$ & $0.66^{* * *}$ & 1.3 \\
Appearance & $0.41^{* * *}$ & $0.67^{* * *}$ & 1.5 \\
Age & $0.43^{* * *}$ & $0.73^{* * *}$ & 2.3 \\
Personality & $0.49^{* * *}$ & $0.75^{* * *}$ & 1.8 \\
Profession & $0.47^{* * *}$ & $0.78^{* * *}$ & 2.5 \\
Learning Style & $0.45^{* * *}$ & $0.75^{* * *}$ & 1.6 \\
Competence & $0.44^{* * *}$ & $0.76^{* * *}$ & 2.3 \\
Interest & $0.45^{* * *}$ & $0.75^{* * *}$ & 2.0 \\
\hline
\end{tabular}

${ }^{* * *} \mathrm{p}<0.001$.

approaches these values. Lastly, the absolute contribution of an indicator to its construct is given by outer loadings. As can be seen in Table 4, every outer loading exceeds the threshold of 0.50 with $\mathrm{p}<0.001$, thereby showing a large contribution in absolute terms.

\subsection{Structural model evaluation}

After the appropriateness of the measurement model has been established, it is now possible to assess the structural model in order to provide evidence for the proposed theoretical relationships. This is done by examining the relationships between constructs, using the path coefficients $\beta$, effect size $\mathrm{f}^{2}$ and the predictive capabilities of the model, using $R^{2}$ (Chin, 2010).

As there is no strong substantive theory of how the outcome variables are related, three separate models regarding the prediction of the outcome variables perceived learning, satisfaction, and confidence are tested. Table 5 shows the results of these model estimations.

The significant paths of these models will be used to extend the basic model to include the outcome variables. Fig. 2 shows the extended SIPS model.

An important step in evaluating the model is the assessment of the coefficient of determination $\left(R^{2}\right)$ of the endogenous

Table 5

Path coefficients of all possible predictor variables on outcome variables.

\begin{tabular}{llll}
\hline Predictor Variables & \multicolumn{2}{l}{ Dependent Variables } & \\
\cline { 2 - 4 } & Perceived Learning & Satisfaction & Confidence \\
\hline Perceived Learning & 1 & $0.552^{* * *}$ & $0.407^{* *}$ \\
Satisfaction & - & 1 & -0.042 \\
Confidence & - & -0.028 & 1 \\
Social Interaction & 0.071 & -0.094 & 0.132 \\
Social Presence & $0.189^{*}$ & 0.056 & 0.102 \\
Social Space & $0.258^{*}$ & $0.300^{* * *}$ & 0.135 \\
\hline
\end{tabular}

${ }^{* * *} \mathrm{p}<0.001 ;{ }^{* *} \mathrm{p}<0.01 ;{ }^{*} \mathrm{p}<0.5$.

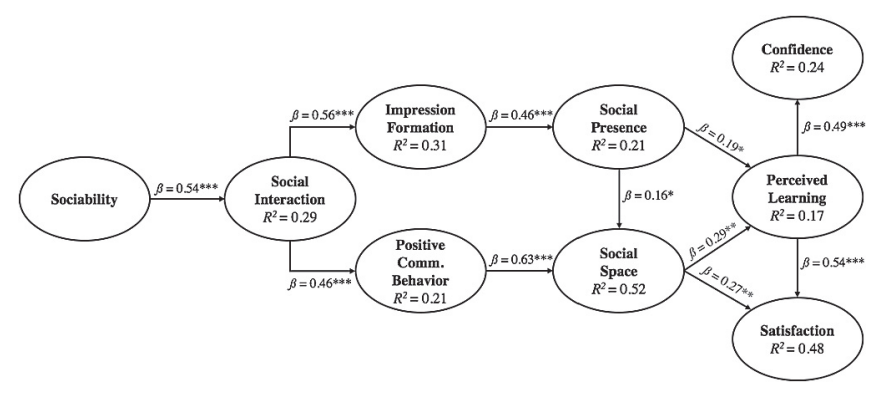

Fig. 2. The SIPS model with path coefficients in $\beta$, variance explained in $R 2$, and outcome variables.
Table 6

$R^{2}$ and $R^{2}$ adjusted.

\begin{tabular}{lll}
\hline & $R^{2}$ & $R^{2}$ adj. \\
\hline Social Interaction & 0.29 & 0.28 \\
Impression Formation & 0.32 & 0.31 \\
Social Presence & 0.22 & 0.21 \\
Pos. Comm. Behav. & 0.21 & 0.20 \\
Social Space & 0.52 & 0.51 \\
Perceived Learning & 0.17 & 0.16 \\
Satisfaction & 0.48 & 0.47 \\
Confidence & 0.24 & 0.23 \\
\hline
\end{tabular}

(dependent) constructs. $R^{2}$ is the amount of variance explained in a given dependent construct by its predictor. Because $R^{2}$ increases even if a non-significant but correlated construct is introduced to the model, $R^{2}$ adjusted should also be considered, as this penalizes increasing model complexity. Table 6 shows that these two measures converge on approximately the same values. All variables show a higher $R^{2}$ than the recommended minimum of 0.10 (Falk \& Miller, 1992) and are therefore adequately explained by the model.

The path coefficients represent the strength of the hypothesized relationships between constructs. Both path coefficients $\beta$ and $R^{2}$ are shown in Fig. 2, along the arrows and in the circles, respectively. To assess the significance of the path coefficients, a bootstrapping procedure was run with the recommended subsample value of 5000 (Hair et al., 2014). The results of this are shown in Table 7.

To determine the effect sizes, Cohen's $f^{2}$ is assessed. This value shows the magnitude of the relative effect a predictor construct has on its dependent construct. Table 7 shows these effect sizes in parentheses. According to Cohen's (1988) guidelines for effect sizes, values of $0.02,0.15$ and 0.35 indicate a small, medium and large effect, respectively. Applying this, there are four large effects on dependent constructs, three medium effects and four small effects.

\section{Interpretation of results}

Results indicate that all hypotheses are supported. The results of data analysis, its interpretation, as well as further results will be discussed in detail below. Refer to Table 8 for a summary.

\subsection{Research question 1}

Is the SIPS-model of online learning valid and what are its predictive capabilities?

H1: The sociability of the online learning environment has a large effect (0.41) on the degree to which social interaction is perceived. Because there are conceivably many other more immediate factors influencing social interaction, sociability explains only about a third (29\%) of its variance. This does however lend strong support to the notion that an indirect, ecological approach via the design of the learning environment is an effective means to foster social interaction in online learning. Therefore, creating sociable learning environments, for example by implementing tools and functions that facilitate easy, seamless and quick communication might be worthwhile consideration when designing online learning experiences.

H2+H3: Social interaction has a large effect (0.46) on impression formation, explaining about a third of its variance (0.31). This supports the hypothesis that interacting with peers allows a learner to form rich and individuating impressions based on certain characteristics like appearance, age, and personality. Impression formation, in turn has a medium to large effect $(0.27)$ on social presence, accounting for about a fifth of its variance (21\%). This indicates that distinct impressions of other learners are indeed an 
Table 7

Path coefficients (and effect size in $f^{2}$ ).

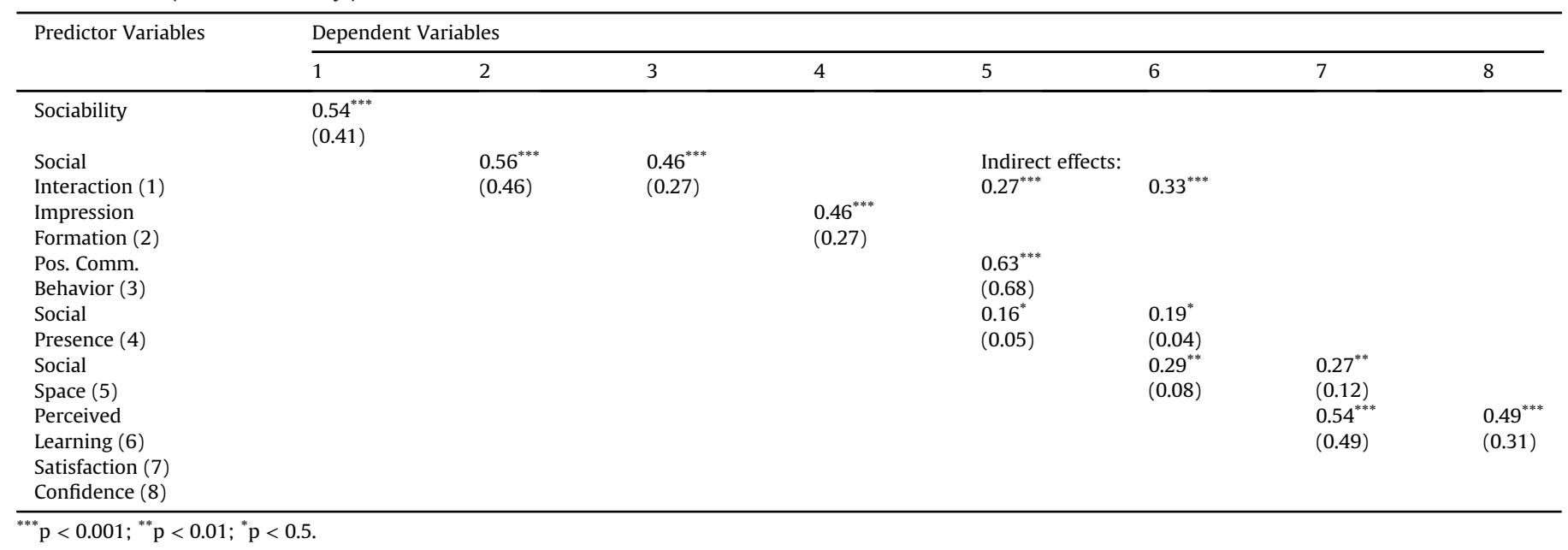

Table 8

Summary of hypotheses tests.

\begin{tabular}{ll}
\hline Hypotheses & This study \\
\hline H1 Sociability is a predictor for social interaction in the learning & supported \\
environment & \\
H2 Social interaction predicts impression formation & supported \\
H3 Impression formation predicts social presence & supported \\
H4 Social interaction predicts positive communicative behavior. & $\begin{array}{l}\text { supported } \\
\text { supported }\end{array}$ \\
H5 Positive communicative behavior predicts a sound social & \\
space & supported \\
H6 Social Presence predicts a sound Social Space & supported \\
H7 Satisfaction is predicted by a sound social space instead of & \\
social presence & supported \\
\hline
\end{tabular}

important precursor to social presence, but that there may be additional factors governing the emergence of social presence outside of this model. A significant indirect effect of social interaction on social presence (0.27) further supports the relationship of these three variables. This means that, if teachers and instructional designers want to foster the experience of social presence, they have to take measures to increase social interaction, as these interactions yield distinct impressions between communicators.

H4+H5: Social Interaction has a medium to large effect (0.27) on positive communicative behavior, accounting for about one fifth (21\%) of its variance. This supports the idea that social interaction is necessary to demonstrate and perceive positive communicative behavior between students. This, in turn has a very large effect (0.68) on the development of a sound social space. Together with social presence, it accounts for about half (52\%) of social space's variance. In order to perceive a sound social space, positive communicative behavior needs to be demonstrated by students. Only then will this positive social climate lead to the development of salient interpersonal connections that form a sound social space. A significant indirect effect of social interaction on social presence (0.33) supports this relationship. Here too, teachers and instructional designers should consider social interaction as a main driver in the emergence of a sound social space.

H6: Social Presence has a small (0.05) effect on social space. Because of its low path coefficients, social presence is expected to contribute only a fraction to the explanation of social space's variance. Although the hypothesis is supported, this relationship is much weaker than expected, implying that the psychological sensation of the other being "there" and "present" contributes marginally to the development of salient interpersonal relationships. This means, that fostering social presence is not enough to achieve a beneficial learning climate and interpersonal connections that form a sound social space. Therefore, separate measures to achieve this should be taken.

\subsection{Research question 2}

How do the outcome variables relate to social aspects of online learning?

H7: The data shows that satisfaction is predicted by a sound social space with a small to medium (0.12) effect, accounting for about half of its variance (48\%) together with perceived learning. Social Presence, however shows no significant relationship to satisfaction. This implies that, although social presence may be desirable for other reasons, its direct connection to satisfaction is at least questionable. The prominent link between social presence and satisfaction seems to disappear after untangling social presence from social space. Instead, a sound social space is predictive of satisfaction with the learning experience. In order to increase the perceived quality of the learning experience, teachers and instructional designers should therefore focus on facilitating the emergence of a sound social space.

H8: Common sense suggests that perceived learning will predict confidence and satisfaction. This is supported by a medium to large effect (0.31) and a large effect (0.49), respectively. Perceived learning accounts for about one fourth (24\%) of the variance of confidence. This means that, although it is a strong predictor, there are other factors influencing a student's confidence in his learning gains. Because of its strong path coefficient to satisfaction, perceived learning is expected to contribute to most of the variance in satisfaction. This means that, even though socio-emotional aspects are important for a satisfying online learning experience, perceived cognitive learning gains remain most essential. Social Presence and Social Space, being rather subjective socioemotional perceptions, have little impact on perceived learning (0.04 and 0.08 , respectively).

This supports the notion that although socioemotional aspects are important in online learning, they can hardly influence actual cognitive learning gains (or even a perception thereof). Similarly, confidence is not predicted by any other variable than perceived learning, demonstrating that social aspects are far outweighed by cognitive aspects when considering the subjective quality of the learning experience. This can be taken to mean, that social aspects, 
especially social space, may be helpful auxiliary variables in improving the perceived quality of the online learning experience, but that (the perception of) cognitive learning gains still are the main driver of satisfaction and confidence. Interestingly, social interaction too, does not predict perceived learning. Although social interaction was operationalized to encompass all kinds of student-student interaction, task or non-task, cognitive or socioemotional, there was no connection to perceived learning.

\section{Discussion}

This study was a first step in empirically validating the distinction between social presence and a sound social space. As the data shows, the classic effect of social presence on satisfaction was not found in this study. Instead, a sound social space seems to be the dominant socioemotional factor driving satisfaction. This result is not in line with previous social presence research, in which the relationship to satisfaction is rather prominent (Richardson et al., 2017). However, as suggested in chapter 2.1 und 2.2, this relationship may be the result of convoluted definitions and measures of social presence. If most social presence scales do indeed measure the extent of a sound social space (Kreijns et al., 2014), the frequency of studies supporting the relationship to satisfaction is not surprising. The finding that a sound social space, not social presence, may be the main driver of satisfaction needs to be replicated in different contexts and with larger samples. Only then can the confusion surrounding social presence and its effects give way to a clearer understanding. We suggest using the Kreijns et al. (2011) scale for this purpose, as it seems to be one of the few validated scales that aim to strictly distinguish social presence from other social variables. As shown in this research, the theoretical and empirical distinction of social presence and social space has explanatory power and should consequently be considered in further research on social aspects of online learning.

In addition, this research is a first attempt in validating the SIPS model, adapted from Kreijns et al. $(2004,2007,2013)$ for a nonCSCL context. The predictive capabilities of the model demonstrate that it is a viable framework for understanding and predicting social aspects of online learning. However, this study also shows that the socioemotional variables, albeit important for the online learning experience, are outweighed by the importance of actually perceiving individual learning progress.

These findings emphasize the importance of designing and implementing sociable learning environments, supporting the ecological approach to fostering social interaction.

Because social interaction, although considered essential, does not always develop automatically (Kreijns, Kirschner, \& Jochems, 2003), the sociability of a learning environment should be a major consideration. Although there has been research to this end (Abedin, Daneshgar, \& D'Ambra, 2010; Gao, Dai, Fan, \& Kang, 2010), further research determining factors of sociability and finding ways to create sociable learning environments is needed. Deliberately designing a sociable learning environment and comparing its effects with a non-sociable learning environment on the emergence of social presence, the development of a sound social space as well as outcome variables is an important next step in validating the model and advancing the ecological approach. So long as there are no established design recommendations to improve the sociability of the learning environment, practitioners may rely on fostering social interaction directly in order to facilitate social presence and the emergence of a sound social space.

This study has several limitations. The analyzed model was streamlined in ways to depict the hypothesized primary causal flow of the relevant variables. This was done in accord with operational definitions of the variables. However, it is possible that bidirectional relationships do indeed exist and their investigation may be an important step in getting the full picture. As of now, the PLS-SEM algorithm does not allow for specification of causal loops and therefore may not be suitable for a more comprehensive analysis of these social variables.

For this research, a rather typical distance education class was chosen. Students communicated predominantly via asynchronous threaded message boards and there was little synchronous activity. In addition, the class size is large ( $>500$ ), suggesting relative anonymity among students. Although this context was explicitly chosen to validate the model and test the hypothesis in a rather exemplary distance education online class, a more ambitious instructional design may lead to stronger effects and higher amounts of explained variance.

Only $32 \%$ of participants took part in the synchronous chat activities. Because of this, the items of the social presence scale that directly relate to chat activities were excluded from analysis. This reduced the scale considerably, possibly limiting its validity.

Also, this study is of correlational nature. The causal claims of the model are rooted in theory, but not strictly falsifiable via this research design. Future studies should try to experimentally manipulate sociability and other antecedent variables in order to reliably identify causal mechanisms that actually lead to the emergence of social presence and a sound social space.

\section{Acknowledgements}

This research did not receive any specific grant from funding agencies in the public, commercial, or not-for-profit sectors.

\section{References}

Abedin, B., Daneshgar, F., \& D'Ambra, J. (2010). Underlying factors of sense of community in asynchronous computer supported collaborative learning environments. Journal of Online Learning and Teaching, 6(3), 585.

Allen, I. E., \& Seaman, J. (2013). Changing course: Ten years of tracking online education in the United States. Sloan Consortium.

Allison, P. D. (2001). Missing data. Sage publications.

Arbaugh, J. B., Cleveland-Innes, M., Diaz, S. R., Garrison, R., Ice, P., Richardson, J., et al. (2008). Developing a community of inquiry instrument: Testing a measure of the community of inquiry framework using a multi-institutional sample. Internet and Higher Education, 11(13), 133-136.

Argyle, M., \& Dean, J. (1965). Eye contact, distance and affiliation. Sociometry, 28, 289-304.

Biocca, F., Harms, C., \& Burgoon, J. K. (2003). Toward a more robust theory and measure of social presence: Review and suggested criteria. Presence, 12(5) 456-480.

Cao, Y., Ajjan, H., \& Hong, P. (2013). Using social media applications for educational outcomes in college teaching: A structural equation analysis. British Journal of Educational Technology, 44(4), 581-593.

Carlon, S., Bennett-Woods, D., Berg, B., Claywell, L., LeDuc, K., Marcisz, N., \& Zenoni, L. (2012). The community of inquiry instrument: Validation and results in online health care disciplines. Computers \& Education, 59(2), 215-221.

Chin, W. W. (1998). The partial least squares approach for structural equation modeling. In G. A. Marcoulides (Ed.), Modern methods for business research. London: Lawrence Erlbaum Associates. pp. 295-236.

Chin, W. W. (2010). How to write up and report PLS analyses. In Handbook of partial least squares (pp. 655-690). Berlin Heidelberg: Springer.

Cohen, J. (1988). Statistical power analysis for the behavioral sciences (2nd ed.) Hillsdale, NJ: Lawrence Erlbaum Associates.

Cui, G., Lockee, B., \& Meng, C. (2013). Building modern online social presence: A review of social presence theory and its instructional design implications for future trends. Education and Information Technologies, 18, 661-685.

Dewiyanti, S., Brand-Gruwel, S., Jochems, W., \& Broers, N. J. (2007). Students' experiences with collaborative learning in asynchronous computer-supported collaborative learning environments. Computers in Human Behavior, 23(1) 496-514.

Diaz, S. R., Swan, K., Ice, P., \& Kupczynski, L. (2010). Student ratings of the importance of survey items, multiplicative factor analysis, and the validity of the community of inquiry survey. Internet and Higher Education, 13(1), 22-30.

Falk, R. F., \& Miller, N. B. (1992). A primer for soft modeling. Akron, OH: University of Akron Press.

Faul, F., Erdfelder, E., Lang, A.-G., \& Buchner, A. (2007). G*Power 3: A flexible statistical power analysis program for the social, behavioral, and biomedical sciences. Behavior Research Methods, 39, 175-191. 
Fillion, G., Limayem, M., Laferriere, T., \& Mantha, R. (2009). Integrating ICT into higher education: Investigating onsite and online professors' points of view. International Journal on E-Learning, 8(1), 17-55.

Fornell, C., \& Larcker, D. F. (1981). Evaluating structural equation models with unobservable variables and measurement error. Journal of Marketing Research 1(18), 39-50.

Forum Distance Learning. (2014). Fernunterrichtsstatistik 2013. Retrieved April. 28, 2015, from http://www.forum-distance-learning.de/fernunterrichtstatistik.

Gao, Q., Dai, Y., Fan, Z., \& Kang, R. (2010). Understanding factors affecting perceived sociability of social software. Computers in Human Behavior, 26(6), 1846-1861.

Garrison, D. R., Anderson, T., \& Archer, W. (2000). Critical thinking in a text-based environment: Computer conferencing in higher education. Internet and Higher Education, 11(2), 1-14.

Garrison, D. R., Anderson, T., \& Archer, W. (2010). The first decade of the community of inquiry framework: A retrospective. Internet and Higher Education, 13(1), 5-9.

Garrison, D. R. \& Arbaugh, J. B. (2007). Researching the community of inquiry framework: Review, issues, and future directions. Internet and Higher Education, 10(3), 157-172.

Graham, J. W. (2009). Missing data analysis: Making it work in the real world. Annual review of Psychology, 60, 549-576.

Gunawardena, C. N. (1995). Social presence theory and implications for interaction and collaborative learning in computer conferences. International Journal of Education Telecommunications, 1, 147-166.

Gunawardena, C. N., \& Zittle, F. (1997). Social presence as a predictor of satisfaction within a computer mediated conferencing environment. American Journal of Distance Education, 11(3), 8-25.

Hair, J. F., Hult, G. T. M., Ringle, C. M., \& Sarstedt, M. (2014). A primer on partial least squares structural equation modeling (PLS-SEM). Thousand Oaks: Sage.

Hair, J. F., Ringle, C. M., \& Sarstedt, M. (2011). PLS-SEM: Indeed a silver bullet. Journal of Marketing theory and Practice, 19(2), 139-152.

Hamari, J., Shernoff, D. J., Rowe, E., Coller, B., Asbell-Clarke, J., \& Edwards, T. (2016). Challenging games help students learn: An empirical study on engagement, flow and immersion in game-based learning. Computers in Human Behavior, 54, $170-179$.

Hostetter, C., \& Busch, M. (2006). Measuring up online: The relationship between social presence and student learning satisfaction. Journal of Scholarship of Teaching and Learning, 6(2), 1-12.

Kim, J. (2010). Developing an instrument to measure social presence in distance higher education. British Journal of Educational Technology, 42(5), 763-777.

Kim, J., Kwon, Y., \& Cho, D. (2011). Investigating factors that influence social presence and learning outcomes in distance higher education. Computers \& Education, 57(2), 1512-1520.

Kreijns, K., Kirschner, P. A., \& Jochems, W. (2002). The sociability of computersupported collaborative learning environments. Educational Technology \& Society, 5(1), 8-22.

Kreijns, K., Kirschner, P. A., \& Jochems, W. (2003). Identifying the pitfalls for social interaction in computer-supported collaborative learning environments: A review of the research. Computers in Human Behavior, 19(3), 335-353.

Kreijns, K., Kirschner, P. A., Jochems, W., \& Van Buuren, H. (2004). Determining sociability, social space, and social presence in (a)synchronous collaborative groups. CyberPsychology \& Behavior, 7(2), 155-172.

Kreijns, K., Kirschner, P. A., Jochems, W., \& Van Buuren, H. (2007). Measuring perceived sociability of computer-supported collaborative learning environments. Computers \& Education, 49(2), 176-192.

Kreijns, K., Kirschner, P. A., Jochems, W., \& Van Buuren, H. (2011). Measuring perceived social presence in distributed learning groups. Education and Information Technologies, 16(4), 365-381.

Kreijns, K., Kirschner, P. A., \& Vermeulen, M. (2013). Social aspects of CSCL environments: A research framework. Educational Psychologist, 48(4), 229-242.

Kreijns, K., Van Acker, F., Vermeulen, M., \& Van Buuren, H. (2014). Community of inquiry: Social presence revisited. E-Learning and Digital Media, 11(1), 5-18.

Liu, S. Y., Gomez, J., \& Yen, C.-J. (2009). Community college online course retention and final grade: Predictablility of social presence. Journal of Interactive Online Learning, 8(2), 165-182.

Lowenthal, P. R. (2010). The evolution and influence of social presence theory on online learning. In T. T. Kidd (Ed.), Online education and adult learning: New frontiers for teaching practices (pp. 124-134). Hershey: IGI Global.

Lowenthal, P. R., \& Dunlap, J. C. (2014). Problems measuring social presence in a community of inquiry. E-Learning and Digital Media, 11(1), 19-30.

Moore, M. G. (1989). Editorial: Three types of interaction. American Journal of Distance Education, 3(2), 1-7.

Picciano, A. G. (2002). Beyond student perceptions: Issues of interaction, presence, and performance in an online course. Journal of Asynchronous Learning Environments, 6(1), 21-40.

Richardson, J. C., \& Swan, K. (2003). Examining social presence in online courses in relation to students' perceived learning and satisfaction. Journal of Asynchronous Learning Networks, 7(1), 68-88.

Richardson, J. C. Maeda, Y., Lv, J., \& Caskurlu, S. (2017). Social presence in relation to students' satisfaction and learning in the online environment: A meta-analysis. Computers in Human Behavior, 71, 402-417.

Richardson, J., Swan, K., Lowenthal, P., \& Ice, P. (2016). Social presence in online learning: Past, present, and future. In Proceedings of global learn 2016 (pp. 477-483). Association for the Advancement of Computing in Education (AACE).

Ringle, C. M., Wende, S., \& Becker, J.-M. (2015). SmartPLS 3. Bönningstedt: SmartPLS. Retrieved from www.smartpls.com.

Rourke, L., Anderson, T., Garrison, D. R., \& Archer, W. (2001). Assessing social presence in asynchronous text-based computer conferencing. Journal of Distance Education, 14(2), 51-70.

Rovai, A. P. (2002). Sense of community, perceived cognitive learning, and persistence in asynchronous learning networks. The Internet and Higher Education, 5(4), 319-332.

Short, J., Williams, E., \& Christie, B. (1976). The social psychology of telecommunications. London: Wiley.

Snyder, T. D., Dillow, S. A., \& Hoffman, C. M. (2009). Digest of education statistics 2008. Washington, DC: National Center for Education Statistics.

Tu, C.-H. (2002). The impacts of text-based CMC on online social presence. Journal of Interactive Online Learning, 1(2), 1-24.

Tu, C. H., \& McIsaac, M. (2002). An examination of social presence to increase interaction in online classes. American Journal of Distance Education, 16(3), $131-150$.

Walther, J. B. (1993). Impression development in computer-mediated interaction. Western Journal of Communication, 57(4), 381-398.

Wei, C.-W., Chen, N.-S., \& Kinshuk. (2012). A model for social presence in online classrooms. Educational Technology Research and Development, 60(3), 529-545.

Wiener, M., \& Mehrabian, A. (1968). Language within language: Immediacy, a channel in verbal communication. Ardent Media.

Wu, J. H., Tennyson, R. D., \& Hsia, T. L. (2010). A study of student satisfaction in a blended e-learning system environment. Computers \& Education, 55(1), 155-164. 